Etnográfica

Revista do Centro em Rede de Investigação em

Antropologia

vol. $23(3) \mid 2019$

Vol. 23 (3)

\title{
Dramas, socializações e treinamentos: as pedagogias jurídicas em uma ONG no Timor-Leste contemporâneo
}

Dramas, socializations and trainings: legal pedagogies in an NGO in

contemporary East-Timor

Miguel Antonio dos Santos Filho

\section{(2) OpenEdition}

\section{Journals}

\section{Edição electrónica}

URL: https://journals.openedition.org/etnografica/7608

DOI: 10.4000/etnografica.7608

ISSN: 2182-2891

\section{Editora}

Centro em Rede de Investigação em Antropologia

\section{Edição impressa}

Data de publição: 1 outubro 2019

Paginação: 755-774

ISSN: 0873-6561

\section{Refêrencia eletrónica}

Miguel Antonio dos Santos Filho, «Dramas, socializações e treinamentos: as pedagogias jurídicas em uma ONG no Timor-Leste contemporâneo», Etnográfica [Online], vol. 23 (3) | 2019, posto online no dia 28 novembro 2019, consultado o 21 janeiro 2022. URL: http://journals.openedition.org/etnografica/ 7608 ; DOI: https://doi.org/10.4000/etnografica.7608

\section{(c) (†) 8}

Etnográfica is licensed under a Creative Commons Attribution-NonCommercial 4.0 International License. 


\section{Dramas, socializações e treinamentos: as pedagogias jurídicas em uma ONG no Timor-Leste contemporâneo}

\section{Miguel Antonio dos Santos Filho}

Este artigo trata de algumas práticas do Fórum para a Comunicação de Mulheres Leste-Timorenses (Forum Komunikasi Untuk Perempuam Lorosa'e - Fokupers), organização não governamental $(\mathrm{ONG})$ atuante no combate à violência doméstica em Timor-Leste. Tais práticas são voltadas às mulheres agredidas e aos jovens engajados com a luta pela igualdade de gênero no país. Tomo-as para discutir os modos como elas são projetadas para estes públicos, analisando seus elementos constitutivos, suas potencialidades e implicações. Entendo-as enquanto recursos de participação social e política que revelam alguns aspectos sobre a sociedade leste-timorense mais ampla - ou ao menos sobre o modo como esta sociedade e seus valores são representados desde os discursos mobilizados pela equipe da ONG. Argumento que tais atividades figuram como pedagogias jurídicas por meio das quais circulam a reorientação de comportamentos e de práticas de mulheres atingidas pela violência doméstica e de outros sujeitos, a instrumentalização de mecanismos legais e, por fim, o acirramento de disputas sobre sistemas concorrenciais de resolução de conflitos.

PALAVRAS-CHAVE: violência doméstica, justiça, reconhecimento, resolução de conflitos, pedagogias jurídicas.

Dramas, socializations and trainings: legal pedagogies in an NGO in contemporary East-Timor - This article focuses on some practices of the Forum for East-Timorese Women's Communication (Komunikasi Untuk Perempuam Lorosa'e - Fokupers), a non-governmental organization (NGO) active in the fight against domestic violence in East-Timor. Such practices are aimed at women directly affected by domestic violence and young people engaged in the struggle for gender equality in the country. I take them to discuss the ways in which they are designed for these audiences by analyzing their constituent elements, their potentials, and their implications. I understand them as resources for social and political participation that reveal some aspects of the broader East-Timorese society - or at least of how this society and its values are represented in the discourses mobilized by the NGO team. I argue that such activities appear as legal pedagogies through which different dimensions flow: the reorientation of behaviors and practices of women affected by domestic violence and other subjects; the instrumentalization of legal mechanisms; and, finally, the intensification of disputes over competitive systems of conflicts resolution.

KEYWORDS: domestic violence, justice, recognition, conflicts resolution, legal pedagogies.

SANTOS FILHO, Miguel Antonio dos (miguel.antonio1993@gmail.com) - Programa de Pós-graduação em Antropologia Social, Universidade de Brasília, Brasil. 


\section{O COMBATE À VIOLÊNCIA DOMÉSTICA EM TIMOR-LESTE:}

\section{A LCVD E A FOKUPERS}

Em julho de 2010 foi promulgada em Timor-Leste a Lei contra a Violência Doméstica (Lei n. ${ }^{\circ} 7 / 2010$, ou LCVD), que define esse tipo de violência como

"qualquer ato ou sequência de atos cometidos num contexto familiar com ou sem coabitação, por um membro da família contra qualquer dos seus membros quando exista uma ascendência nomeadamente física ou econômica na relação familiar, ou por uma pessoa em relação a outra com a qual teve um relacionamento íntimo, do qual ou dos quais resultem ou possam resultar danos ou sofrimento físico, sexual ou psicológico, abuso econômico, incluindo ameaças tais como atos intimidatórios, ofensas corporais, agressões, coações, assédio ou privação da liberdade" [artigo $\left.2 .^{\circ}\right] .{ }^{1}$

A lei caracteriza como formas de violência doméstica a violência física, sexual, psicológica e econômica entre outras; estas não citadas diretamente. Nas considerações do documento sobre a violência física, esta é "entendida como qualquer conduta que ofenda a integridade ou saúde corporal" de um indivíduo (artigo $2 .^{\circ}$ ). O Código Penal do país, vigente desde 2009, nos artigos $153 .^{\circ}$ a $156 .^{\circ}$ caracteriza os crimes de violência doméstica pelos atos de maus-tratos a incapazes, aos cônjuges ou a menores e pelos agravamentos dos resultados, além de prever os atos ilícitos tratados entre os artigos $138 .^{\circ}$ e $179 .^{\circ}$ (cf. Lei n. ${ }^{\circ} 7 / 2010$, artigo $\left.35 .^{\circ}\right)^{2}$

Para além das definições e previsões legais, instaurou-se no país um longo período para "negociação" do que seriam atos de violência doméstica, ou violénsia doméstika, como é mobilizada localmente a categoria desde o início dos anos 2000 (Simião 2015). As compreensões do que seria a violénsia doméstika foram significativamente discutidas e disputadas naquele período, por haver discordâncias sobre as possibilidades e sobre a legitimidade do uso da força física entre casais e familiares. Desde alguns pontos de vista locais, por exemplo, não seria violência se as agressões tivessem intenções de "educar" ou se

l Na reprodução do texto da lei, mantenho a grafia da língua portuguesa utilizada em Timor-Leste, mais próxima às regras gramaticais do português de Portugal. A Lei n. ${ }^{0} 7 / 2010$ está disponível em português em < http://www.mj.gov.tl/jornal/?q=node/829>, e em tétum (Lei Kontra Violénsia Doméstika) em $<$ http://jsmp.tl/wp-content/uploads/2013/08/LeiKontraViolenciaDomestika-No-7-2010-Tetum.pdf > (última consulta em outubro de 2019). Este texto é fruto de uma pesquisa realizada em Timor-Leste viabilizada pelo programa de mobilidade acadêmica da Coordenação de Aperfeiçoamento de Pessoal de Nível Superior (Capes) por meio da Associação das Universidades de Língua Portuguesa (AULP), de acordo com o edital n. ${ }^{\circ}$ 33/2012 (Pró-Mobilidade Internacional - Brasileiros). Meus sinceros agradecimentos à Capes e ao engajamento da professora Kelly Silva no sucesso desta parceria.

2 O Código Penal leste-timorense está disponível em < http://www.mj.gov.tl/jornal/files/Codigo_Pena 1.pdf > (última consulta em outubro de 2019). 
fossem "feitas para o bem", para ensinar o melhor comportamento aos sujeitos (Simião 2015: 126). Para os defensores destas perspectivas, havia situações legítimas para se recorrer às agressões físicas, bem como níveis aceitáveis para estas. Em pesquisa estatística de 2003, verificou-se, por exemplo, que $51 \%$ das mulheres consideravam que um marido deveria bater em sua esposa caso esta lhe desobedecesse e $84 \%$ delas acreditavam que tais casos deveriam ser resolvidos dentro da família (Simião 2015: 122).

Para vários atores, o ato de agredir fisicamente uma mulher seria menos ofensivo do que adultérios, contrações de novos casamentos ou outras decisões tomadas que não contemplassem as vontades das esposas. Isso poderia ser visto, naquele momento, como moralmente mais ofensivo do que tapas ou outras agressões físicas. Tratava-se, então, de um processo de invenção da violénsia doméstika como algo moralmente condenável (Simião 2015), dando novos enquadramentos morais (Geertz 1997) para os conflitos conjugais marcados pelo uso da força física.

A condenação moral da violência doméstica impulsionou a criação da Lei n. ${ }^{\circ} 7 / 2010$, dando vazão para que uma série de atores se engajasse, desde aquele período, em campanhas de conscientização sobre violência doméstica e sexual, igualdade de gênero, direitos das mulheres e, ainda, na criação de espaços de atendimento e de acolhimento para aquelas atingidas pela violência baseada em gênero. ${ }^{3}$ Este tipo de trabalho, que já existia antes mesmo da promulgação da LCVD, ganhou novos fôlegos, pois a partir de então, além de estar amparado por uma legislação que atendia a antigos pleitos, poderia desenvolver novas funções com as recentes previsões legais.

Foi com a promulgação da Lei n. ${ }^{\circ} 7 / 2010$ que os casos entendidos, agora formalmente, como sendo de violência doméstica passaram ao status de crimes públicos, como definido em seu artigo $36^{\circ}{ }^{\circ}$. Muitos dos documentos e das manifestações de movimentos de mulheres, instituições estatais, ONGs e ativistas reivindicaram (e ainda reivindicam) que os casos de violência baseados em gênero deveriam ser de tutela judicial, por considerarem, entre outras coisas, que as esferas ditas tradicionais ou da cultura para administração de conflitos não dariam o tratamento adequado aos casos e às situações das mulheres vítimas de violências, expondo-as a constrangimentos e a eventuais revitimizações (GPI 2003; Fokupers 2012a, 2012b; SEPI 2012; JSMP 2013). Parte dos problemas percebidos por estes agentes seria devida a que essas formas locais de resolução de conflito não estariam interessadas em assegurar a reparação dos direitos das mulheres em especial, atuando apenas para a manutenção da integridade das relações entre famílias (GPI 2003). ${ }^{4}$ Outro problema, entendido

3 Processo iniciado no país desde meados da década de 90, como apontado por Jannisa (2002), Hunt (2004), Simião (2015) e Santos Filho (2016).

4 Uma discussão etnográfica a esse respeito foi produzida por Daniel Simião (2007). 
por estes agentes, era o de que, nessas esferas de resolução de conflitos não judiciais, as autoridades locais imputariam penas às mulheres, que deveriam pagar compensações à família do marido, por entenderem que, mesmo tendo sido agredida, a mulher teria parte da responsabilidade pela agressão sofrida (Fokupers 2012b).

Somados, o reconhecimento da gravidade da violência doméstica, as garantias legais previstas na LCVD, a luta pela igualdade de gênero e pelos direitos das mulheres e os interesses em ampliar e disseminar conhecimento sobre a violência doméstica e sobre as formas de combatê-la institucionalmente, formam o centro discursivo e de embasamento para a atuação da Fokupers. É a este conjunto de orientações que deveremos estar atentos para compreender as atividades desenvolvidas e as posturas adotadas por ela e por seus agentes.

Acompanhando o Setor de Assistência Legal da Fokupers entre 2015 e 2016, pude dialogar com membros daquela equipe, com alguns de seus parceiros institucionais e com as mulheres atendidas pela Fokupers. O Setor de Assistência Legal era chefiado pelo advogado Dr. Mario, pelas bacharelas em direito Augusta e Lia e por Ângela: personagens-chave nas descrições que se seguem. ${ }^{5}$ Esse setor era responsável pelo recebimento das mulheres que chegavam à $\mathrm{ONG}$, tendo elas registrado ou não denúncias de violência doméstica ou sexual, dando início aos devidos procedimentos cabíveis: encaminhamento à polícia para prestarem queixa, acareação pela necessidade de abrigo, orientações preliminares ou encaminhamento aos serviços de saúde. Fundamental para a presente discussão é entender que era atribuição daquele setor fazer a mediação entre as mulheres que foram agredidas e as instâncias de polícia, ministério público, casas abrigo e, posteriormente, os tribunais. ${ }^{6}$

As mulheres recebidas pela organização e acolhidas em sua casa abrigo (a Uma Mahon) são chamadas de mitra. Mitra é um termo da língua indonésia e significa "parceira". Ele é utilizado no lugar da palavra "vítima", para diminuir a distância entre a organização e as mulheres atendidas por ela, e para retirá-las da posição passiva de "vítimas", engajando-as no processo de recuperação de seus traumas.

O funcionamento do Setor de Assistência Legal e os mecanismos produzidos e acionados para garantir a participação das mitra nos processos judiciais de violência doméstica têm caráter central na vida social e na rotina da ONG. Dentre o complexo de serviços prestados, destaca-se o seu papel no acompanhamento das mulheres aos tribunais e às audiências. A Fokupers

5 Os nomes dos membros da equipe da ONG serão substituídos por nomes fictícios, a fim de resguardar suas identidades.

6 Todos os procedimentos de acolhimento e de atendimento às vítimas estão sistematizados em outros trabalhos (Santos Filho 2016, 2017) e, pelas limitações desta discussão, serão apresentados de modo resumido. 
garante o transporte das mulheres, se encarregando do trânsito entre a capital e os municípios e vice-versa, para assegurar a presença delas nas audiências. ${ }^{7}$ Além disso, a Fokupers as acompanha nos encaminhamentos procedimentais necessários: cuida de sua assiduidade e pontualidade nos julgamentos e da identificação aos oficiais quando de sua chegada, e não deixa que restem dúvidas sobre as decisões provenientes das sessões, explicando os procedimentos tomados pelos juízes, promotores e defensores e traduzindo aquilo que foi firmado em juízo.

Garantir que as mitra estejam lá e que compreendam minimamente o que está sendo feito, dito e negociado é apenas parte, ou uma das faces, do que assegura a participação das mulheres naquele universo jurídico-judicial. Frequentar corporalmente as esferas judiciais é, sem dúvida, parte fundamental da participação das mulheres em processos comandados por lógicas jurídicas de Estado; entretanto, a Fokupers se encarrega de produzir outro conjunto de mediações que visam familiarizá-las ao universo jurídico estatal, isto é, ensinar as mulheres a participarem dele.

Proponho que analisemos três tipos de atividades para que compreendamos a atuação da equipe como mentora das mitra em sua participação ativa e consciente nas esferas judiciais (acionamento da polícia e recurso aos tribunais) e jurídica (defesa de seus direitos e pela igualdade de gênero) do Estado moderno. Estas atividades, que entendo como pedagogias jurídicas, serão apresentadas em três tipos: as atividades de drama (encenações das audiências nos tribunais, cujo objetivo é preparar as mitra, adequando seus comportamentos àquele contexto específico); as atividades de socialização (com caráter preparatório e de orientação mais ampla, familiarizando as mitra com o universo jurídico que cerca os conflitos de violência doméstica e as demandas pela garantia dos direitos das mulheres); e, por último, o treinamento de multiplicadores (cujo objetivo é instruir pessoas engajadas na luta pela igualdade de gênero a se valerem de determinados instrumentos, qualificando suas atuações nas comunidades pelo país).

\section{DRAMATIZANDO JULGAMENTOS, SOCIALIZANDO LEIS E MULTIPLICANDO SABERES}

Numa atividade de "drama" da qual participei ao lado de Augusta e de Ângela, fica claro o caráter educativo da atividade. ${ }^{8}$ A missão naquele dia era preparar Betânia para a audiência na qual seria avaliada a situação judicial dela com seu

7 Tarefa de grande relevância, uma vez que frequentemente as audiências ocorrem em outros municípios que não aqueles de residência das mitra.

8 O termo "drama" é corrente na rotina da Fokupers para se referir às encenações teatrais das audiências e julgamentos. 
vizinho. ${ }^{9} \mathrm{O}$ conflito se desencadeou meses antes, quando este último deu uma festa que durou um dia inteiro, se estendendo pela madrugada com música alta. Incomodada, Betânia o procurou no dia seguinte dizendo que relataria o ocorrido à polícia e ao chefe de suku. ${ }^{10}$ Irritado, o vizinho deu-lhe dois chutes, o que levou Betânia a denunciá-lo para a polícia pela agressão.

Na semana do julgamento, Betânia foi recebida na sala do Setor de Assistência Legal para participar de uma atividade que visava orientar a conduta que deveria adotar no tribunal. Para que ela aprendesse o que deveria fazer procedeu-se, assim, com o "drama" do julgamento. Ângela representava o defensor público, explicando-lhe que aquela figura era nomeada para interceder na defesa do arguido. Participei representando o ministério público, o promotor, tendo meu papel também explicado para Betânia: aquele que estava cuidando de seu interesse, cobrando pela garantia de seus direitos. Por último, Augusta representava a juíza, vestindo uma toga preta e portando um malhete. "Esta é a juíza, tratada como meritíssima, ela julga o caso e decide o que vai acontecer com o arguido", dizia Ângela, em sua explicação detalhada sobre quem era, o que representava e, por fim, o que fazia cada personagem naquela cena.

Betânia era orientada por Ângela sobre todos os passos que deveria desempenhar naquele contexto. Desde levantar-se quando entrasse o juiz - assim permanecendo até que ele pedisse para que todos se sentassem - até a forma como ela deveria se referir a ele, tudo era explicado com bastante cautela. As agentes do Setor de Assistência Legal recomendavam ainda que Betânia aceitasse a oportunidade de fala quando oferecida pelo juiz, no momento em que este desse a ela as opções de falar por si mesma sobre o incidente com o vizinho ou deixar que o representante do ministério público o fizesse.

"Falar" era parte fundamental no procedimento de orientação fornecido pela equipe. Elas não se limitavam a explicar os termos e nomenclaturas que comporiam a situação vindoura; se preocupavam antes com o que e como a mitra iria falar na audiência. Betânia era advertida sobre dever cuidar de sua postura ao se sentar e ao se levantar, falando em tom de voz firme e em uma altura "adequada" (nem baixo nem muito alto), e Ângela a advertiu de que era importante responder ao juiz com precisão sobre suas informações pessoais: dia, mês e ano de nascimento, sua idade, o local onde nasceu e seu nome de registro completo. Durante a atividade, Betânia teve de conferir seus documentos duas vezes para que memorizasse estes dados, já que não os tinha com muita clareza na memória. Do mesmo modo, Betânia foi orientada

9 Apesar de o caso não ser de violência doméstica, este se enquadrava enquanto violência contra a mulher e era, segundo a equipe de assistência legal, assunto de interesse da ONG pela relação de proximidade entre as partes.

10 Suku é uma unidade administrativa que congrega um conjunto de aldeias sob a administração de um chefe de suku eleito através de eleições diretas. 
sobre recontar os fatos com riqueza de detalhes: a duração da festa dada pelo vizinho, o dia e a hora, o modo como interpelara aquele homem, bem como a forma agressiva como ele respondera. Era importante construir bem a narrativa do acontecimento para expô-lo ao juiz, combinando-a a uma postura firme, de alguém que estava consciente de ter tido seus direitos infligidos pelo arguido.

O próprio termo "arguido" mereceu detalhamento da equipe presente. $\mathrm{O}$ arguido era seu vizinho, aquele que foi acusado de tê-la agredido e que seria inquirido sobre ter cometido tal ato e, com isso, ferido tanto física quanto moral e legalmente Betânia. A outra parte daquela lide era ela própria, que, por sua vez, seria referida no julgamento como a "lesada", aquela que sofreu com $o$ ato daquele homem. A explicação dos termos empregados naquele universo jurídico, com os quais se referiam às partes conflitantes e aos operadores do direito envolvidos, é interessante para ser pensada por seu caráter pedagógico, onde os termos necessitam ser apresentados, traduzidos, e - parece adequado dizer - ensinados para as mitra.

A dramatização desde o início, com a entrada da juíza Augusta, a apresentação do caso, a exposição de cada uma das partes e as orientações comportamentais eram repetidas duas, três vezes se fosse preciso, para assegurar que, no momento do julgamento, a mitra saberia exatamente o que e como falar perante o juiz. Deste modo, Betânia tinha sua postura treinada, projetando sua adequação ao universo jurídico-judicial no qual seria inserida. Mais do que entender o léxico de categorias daquele sistema, construía-se um espaço de fornecimento de ferramentas para que ela pudesse atuar de modo mais capacitado na nova esfera jurídica.

Este tipo de preparação focada nas audiências dividia espaço na rotina executiva do Setor de Assistência Legal com as "socializações", atividades realizadas com grupos de mitra cuja finalidade principal era o compartilhamento de certas concepções sobre formas de se lidar judicialmente com a violência doméstica e vistas como recurso na luta pela igualdade de gênero. Para uma atividade de socialização organizada pela Fokupers, foram levadas as mitra que estavam acolhidas na casa abrigo e outras que, apesar de já terem deixado o abrigo, continuavam recebendo orientações do setor e suporte da ONG. Durante toda a manhã, a atividade funcionou como um workshop sobre direito, no qual Dr. Mario falou da LCVD, da Declaração dos Direitos Humanos, do Código Penal e do Código do Processo Penal leste-timorenses. Mais do que apresentar os textos, a atividade se propunha apresentá-los às mitra como instrumentos que as amparavam a si mesmas e aos seus direitos. Era tratando do conteúdo previsto naqueles documentos que o advogado sistematizava os modos de operação e de funcionamento legal que vigoravam no "governo de Timor-Leste". Aqueles mecanismos da "justiça do Estado" funcionavam "para proteger as mulheres", cada um a seu modo: a Lei n. ${ }^{0} 7 / 2010$ definia que as 
agressões dos maridos eram crimes, estes seriam punidos de acordo com o Código Penal, e assim sucessivamente.

Utilizando os relatos de algumas das mitra, Dr. Mario explicou os tipos de "maus-tratos" - termo definido na LCVD - que configuravam os tapas, empurrões, puxões de cabelo, os sacolejos e outras atitudes agressivas, como rasgar roupas ou atirar objetos. As ameaças, pressões psicológicas, xingamentos e ofensas também entravam como formas de abuso que deveriam ser percebidas como violência doméstica. E elas se encontravam naqueles textos: na Lei n. ${ }^{\circ} 7 / 2010$, no Código Penal e, com toda a legitimidade de que gozavam, mostravam tanto a seriedade daqueles atos quanto sua inadmissibilidade, dado o caráter nocivo aos direitos humanos e à dignidade daquelas mulheres.

Eram noções como estas que as mitra deveriam conhecer para ressignificar suas experiências e, mais que isso, compartilhá-las em suas comunidades com as mulheres e com todos em suas famílias, aldeias e sukus. O ponto central era mostrar que tais atitudes de violência doméstica eram crimes que violavam os direitos das mulheres e que havia previsões legais para responder a essas violações. Na condição de crimes públicos, explicava o advogado, as ocorrências de violência doméstica imputavam a todos, inclusive àquelas mulheres, a obrigação de as denunciarem sempre que tivessem conhecimento de agressões e, ainda, estimulava que elas deveriam alertar outras mulheres a denunciarem as que sofressem.

Esta era a oportunidade para "socializar" a ideia de que a esfera adequada para se lidar com casos daquele tipo era a da justiça do Estado e não a da família, a "justiça tradicional" ou a "cultura". Lá, Dr. Mario ressaltava que muitas mulheres procuravam as autoridades locais ou a família e não conseguiam resolver seus problemas porque, muitas vezes, seriam responsabilizadas pelas agressões que haviam sofrido. Seria apenas através da justiça do Estado que elas responderiam com a rigidez adequada às violências sofridas.

A última atividade que tomarei como referencial das ações da Fokupers é um "treinamento de multiplicadores", organizado num salão alugado em Dili. ${ }^{11}$ O treinamento durou três dias inteiros, com um público formado por pessoas da capital e de outros municípios do país. Intercalando dinâmicas de grupo, trabalhos coletivos e momentos de exposição oral e audiovisual por parte dos membros da equipe da Fokupers, a atividade tinha como objetivo capacitar

ll Por uma questão de tradução, adotarei aqui a designação "treinamento de multiplicadores", mas ressalta-se que o nome em inglês dado pela Fokupers à atividade foi training of trainers (treinamento de treinadores, literalmente). Entendo que a tradução mais coerente no português utilizado no Brasil seria a expressão adotada aqui, uma vez que os agentes treinados pela ONG não iriam dar, exclusivamente, treinamentos para outros agentes em suas comunidades, mas sim atuar mediando e disseminando os saberes adquiridos na atividade para seus ciclos sociais de modo mais geral: família, comunidades, lideranças comunitárias, escolas etc. Deste modo, por serem mais do que treinadores, traduzo sua função como sendo de multiplicadores. 
os participantes a "disseminarem informações" sobre violência doméstica e formas de responder a ela, sobre igualdade de gênero e, por fim, sobre os direitos das mulheres. Os cerca de 25 jovens que participaram do treinamento receberam um volumoso kit que continha apostilas, folders, revistas, materiais informativos e instrutivos que, além de tratar da igualdade de gênero, da violência doméstica e dos direitos das mulheres, se referiam a temáticas de assédio sexual, abuso de menores e incesto. Neste texto apresento as características e objetivos do texto da CEDAW, Convenção sobre a Eliminação de Todas as Formas de Discriminação contra a Mulher (Unifem 2007), da apostila explicativa elaborada pela Fokupers e do material que qualificava os tipos de violência doméstica (também elaborado pela ONG).

No treinamento, as apostilas preparadas pela Fokupers eram projetadas numa das paredes do salão. Os participantes, dispostos ora em fileiras de cadeiras, ora em círculo, acompanhavam os slides lendo sua versão impressa. As dirigentes da atividade liam o conteúdo e discutiam com os participantes, esclarecendo eventuais dúvidas. Baseando-se na Lei n. ${ }^{\circ}$ 7/2010 e na ratificação da CEDAW pela República Democrática de Timor-Leste, bem como amparada por toda a discussão dos direitos humanos, a equipe da ONG munia os participantes com os argumentos de que eles precisariam para defender os direitos das mulheres e para se colocarem como multiplicadores dos ideais da e para a igualdade de gênero.

A apresentação da CEDAW, por exemplo, baseava-se nas considerações de que as comunidades tendiam a perpetuar formas de discriminação contra as mulheres, definindo como razão principal para tal fenômeno a própria condição sexual e de gênero delas. Por ser signatário da convenção, o Estado de Timor-Leste se comprometia a condenar aquelas práticas, tornando-se parceiro engajado na produção da igualdade entre homens e mulheres como princípio fundamental e erradicando as formas de discriminação contra estas últimas. As mulheres, segundo o documento, deveriam ter assegurados seus direitos a disputarem vagas de trabalho em igualdade com os homens, a terem capacitação e a receberem salários em pé de igualdade e, entre outras coisas, a receberem acesso à educação na mesma medida que os homens (Unifem 2007). Em todas as áreas (social, política e econômica), as mulheres deveriam ser respeitadas e tratadas com dignidade, garantindo o princípio da igualdade.

Juntamente com a apresentação da CEDAW vinha a das previsões dos direitos humanos universais, tais como o direito à educação, bom tratamento de saúde, oportunidades sem discriminação pela condição de mulher, participação ativa na vida política, direito de viver sem experimentar nenhuma forma de violência, direito à informação, direito de viver em paz e harmonia, direito à moradia e à terra, a viver bem com a família e com seu parceiro, a ter água, eletricidade, transporte e comunicação, que deveriam ser garantidos às mulheres. 
No documento de apresentação sobre violência doméstica, a Fokupers sistematizou ano a ano o número de ocorrências notificadas pela organização entre 2007 e 2012: 956 casos. A apresentação se preocupava em definir o que configurava violência doméstica e como ela impactava a vida das mulheres. $\mathrm{Na}$ sistematização da ONG, a violência doméstica era definida como algo que acontecia nas casas e nas famílias, de modo que o marido bateria na mulher e, como algo cíclico, a mulher bateria nos filhos, os tios nos sobrinhos, os irmãos mais velhos nas irmãs mais novas, os cunhados se agrediriam e, enfim, atos como estes produziriam ofensas diretas e indiretas à dignidade humana dos sujeitos. Após as definições, o documento seguia durante várias páginas com fotos de mulheres agredidas, com hematomas, escoriações graves e cicatrizes severas que auxiliavam a construir a "imagem" (negativa) dos atos de violência doméstica.

Este mesmo documento de caracterização e de orientação da conduta dos treinadores enfatizava a instrução de que a violência doméstica era um crime público, pois sua ocorrência - nos termos do documento - "é contra o interesse público, porque pode impactar a vida das pessoas, causando: aleijamento, mortes, atingir a dignidade e os direitos humanos". Registravam-se ali várias das possibilidades que desencadeariam os atos de violência física, econômica, sexual e psicológica, dentre os quais o abuso de álcool, o desemprego, a falta de controle do dinheiro da família, a falta de habilidades para produzir boa comunicação, a poligamia, características culturais patriarcais, etc. Em todos os materiais pairava a concepção de que "a violência ofende" invariavelmente e, tomando isso como um pressuposto, os efeitos da violência doméstica seriam mulheres traumatizadas, com poucas habilidades sociais e para o trabalho, que carregariam cicatrizes sociais profundas.

As estratégias da organização para recorrer à CEDAW, à declaração dos direitos humanos e ao embasamento legal para a definição e tratamento da violência doméstica pareciam ser modos de conferir legitimidade àquela agenda política de defesa dos direitos das mulheres que era compartilhada com os participantes do treinamento. As organizadoras entendiam que, por meio da capacitação, os agentes multiplicadores se fariam aptos a organizarem atividades em suas comunidades para compartilharem exatamente aquilo que haviam aprendido. Eles estariam municiados de argumentos, de documentos legais e de formas de guiar discussões que objetivassem a disseminação das mesmas concepções para outras pessoas, produzindo sua capacitação pessoal de modo a potencializarem-se como multiplicadores das concepções igualitaristas e de defesa das formas judiciais de resolução de conflitos. 


\section{PEDAGOGIAS JURÍDICAS}

Enquanto fórum de comunicação, a Fokupers tem se dedicado à disseminação de informações de cunhos variados para auxiliar na luta pelos direitos das mulheres e na produção da igualdade de gênero. Por meio de atividades como as de drama, socialização e treinamento de multiplicadores, fica aparente o potencial de suas propostas para a apreensão de alguns fenômenos postos em curso. Argumento que aquele fórum tem fomentado processos pedagógicos que ensinam às mulheres e aos jovens engajados na luta pela igualdade de gênero a importância do recurso às instâncias judiciais em seus cotidianos, em especial quando se depararem com situações de violência doméstica.

$\mathrm{Na}$ primeira atividade, aquela que visava preparar Betânia para a audiência, a equipe do Setor de Assistência Legal produzia uma tradução do sistema formal de justiça à medida que, literalmente, apresentava os termos técnicos e as figuras que viriam a compor a audiência no tribunal. Betânia era orientada a reproduzir ações específicas, especiais, de certa forma: levantar e sentar-se, requerer a fala, ser precisa nas informações pessoais, contar detalhadamente o que se passara no dia da agressão, falar com segurança, etc. Ela deveria agir, falar e se portar de acordo com as regras do novo universo jurídico-judicial, cujo funcionamento era bastante distinto daquele das formas locais de resolução de conflito que operam nas aldeias leste-timorenses (Simião 2005, 2007, 2015). No tribunal, Betânia seria apenas Betânia, moradora de Dili, lesada no caso e representada pelo promotor, que estaria numa lide judicial contra seu vizinho, arguido no caso. Não haveria, como no universo mais geral dos vários processos de resolução de disputas das aldeias, o encaixe de ambos, representados por seus familiares, numa cerimônia onde todos se sentariam "sobre esteiras" e onde se averiguaria qual o peso das ações de cada um (Simião 2005). Contava apenas o fato da agressão contra Betânia, independentemente de suas motivações ou atenuantes, o que seria impensável nas formas locais de resolução de disputas. Nestas últimas, em outras palavras, o que importa aos mediadores é "buscar motivações: o que motivou a ação que resultou na queixa? O julgamento é um processo de expor razões, e a pergunta central disso tudo é: por quê (tamba sa)?" (Simião 2015: 235).

Se nas esferas locais de mediação de conflitos operam lógicas de mútua responsabilização pelos conflitos, no direito positivo, de inspiração moderno-ocidental, opera-se na busca pela "verdade real", produzida pelo juiz a partir de sua apreciação e de seu convencimento (motivado), concluindo que os sujeitos tidos como "partes" nos processos são culpados ou inocentes, atribuindo-lhes culpa e penalizações que, em tese, pesam contra apenas uma das partes - os ofensores (Oliveira 2011). Essa "objetividade" marcante do direito positivo pode divergir de outras leituras jurídicas sobre o mundo, principalmente quando aplicada a pessoas muitas vezes oriundas de socialidades que utilizam 
formas de resolução de conflitos que não supõem uma parte inteiramente culpada e outra parte completamente inocente, como é o caso de Timor-Leste (Simião 2005: 137-138). A pouca familiaridade de boa parte das mitra com o universo judicial explicaria o investimento da ONG em prepará-las para as audiências, recorrendo, portanto, a estratégias que tornassem mais palpável o universo dos tribunais.

A atividade de socialização, por sua vez, tinha possibilidades de eficiência ampliadas - no sentido de disseminar concepções sobre o acesso à justiça (do Estado) e sobre o exercício de direitos. Sua missão aparente era defender que a forma adequada de se lidar com casos de violência doméstica era através da justiça do Estado, procurando a polícia e dando os encaminhamentos cabíveis a esses casos, evitando, portanto, as esferas locais de resolução de conflitos ou mesmo a prática de "resolver na família". As críticas dos agentes da organização referentes às formas locais de mediação de conflitos em casos de violência doméstica contra as mulheres se centravam no modo como a dita "justiça tradicional" estaria mais preocupada com a manutenção dos vínculos entre grupos gerados por meio das relações familiares e de casamentos, deixando em segundo plano os direitos individuais das mulheres. Era justamente essa maneira de produzir justiça que incomodava os agentes da Fokupers e de instituições estatais ou parceiros destas nos cenários mais amplos de luta pela igualdade de gênero. Para eles, a atenção deveria ser direcionada aos direitos das mulheres, à sua reparação e à sua condição de vulnerabilidade. Outro problema entendido por esses agentes era que, nessas esferas de resolução de conflitos não judiciais, as autoridades locais imputariam penas às mulheres, que deveriam pagar compensações à família do marido, uma vez que estas autoridades entenderiam que, mesmo tendo sido agredidas, as mulheres teriam parte da responsabilidade pela agressão sofrida (Fokupers 2012b). Esse dilema entre as sensibilidades jurídicas (Geertz 1997) das formas locais de mediação de conflitos e aquelas das organizações e instituições de governo é de grande relevância neste contexto, pois permite acessar uma complexa trama discursiva, política e administrativa que se debruça sobre sujeitos, direitos e formas de produção de justiça. Tais controvérsias podem ser percebidas no desenvolvimento destas atividades de socialização empreendidas pela organização.

O treinamento de multiplicadores, por fim, operava numa terceira dimensão de disseminação de saberes, incidindo sobre formas de pensar os atos de uso da força física nas relações conjugais. Se nas socializações o foco ou a partícula disseminadora daquele saber eram as próprias mulheres que vivenciaram violência exercida contra si, no treinamento de multiplicadores os alvos eram jovens engajados com as pautas políticas da igualdade de gênero e do combate à violência contra a mulher. Trata-se, neste último caso, de um nível no qual essas pessoas, ao organizarem atividades de disseminação, atingiriam ainda mais pessoas nas comunidades, pois não estariam lidando exclusivamente com 
mulheres que tivessem sofrido agressões momentâneas. Eles atuariam como agentes de prevenção, conscientizando a população, tanto sobre agressões (físicas, psicológicas, econômicas e sexuais) que elas, eventualmente, não reconheceriam como violência doméstica, quanto orientando os passos adequados para se lidar com as ocorrências e produzir justiça. É fundamental ressaltar que suas agências eram municiadas de embasamento jurídico-legal e que partilhavam, ainda, de moralidades socialmente legitimadas pelo campo das instituições e organizações públicas que cuidavam dos direitos das mulheres.

O que todas estas atividades têm em comum, me parece, é a potencialidade "reorientadora" através de práticas educativas de cunho jurídico: elas pretendem orientar e reorientar sujeitos, no sentido de produzir novas formas de ação, novas formas de ver o mundo, novos modos de ser e de se portar diante de situações cotidianas, novos modos de intervir na vida social e novas formas de interação com sujeitos e com instituições (tanto "tradicionais" ou da "cultura" quanto estatais). A reorientação não partia do zero; era, sobretudo, fundada numa lógica jurídica particular, aquela do direito positivo, da defesa das instituições legais e do reconhecimento do indivíduo portador de direitos inalienáveis e, idealmente, invioláveis.

É certo que as discussões sobre o que seria este "direito" - que serve como base das ações de (re)orientação preparadas pela Fokupers - são longas e inconclusivas (Moore 1978). Em seu ensaio basilar para a antropologia jurídica, Geertz apresenta o direito como forma de ver o mundo social, indicando o modo pelo qual diferentes leituras produzem diferentes noções jurídicas para o ordenamento coletivo (Geertz 1997: 259). Isso implica em compreender que o direito, enquanto forma de imaginar o mundo social, é acompanhado de um conjunto de atitudes práticas sobre o gerenciamento de disputas que ele mesmo "impõe aos que a ela [à visão do direito] se apegam" (Geertz 1997: 275-276). Em diálogo, Lawrence Rosen (2006) sugeriu que o direito seria produto da experiência humana criada por seus próprios atores, num processo que juntaria ideias, valores e significados coletivamente atribuídos aos fenômenos. Para este autor, o direito seria, portanto, um domínio da vida como os espaços de mercado e de troca ou como os papeis familiares: um projeto tanto criativo quanto racionalizado. De modo algo similar à ideia de Roy Wagner (1981) de que os sujeitos são os responsáveis por criarem e recriarem sua cultura, o direito seria também fruto das capacidades e dos esforços criativos do mundo social.

Resumidamente, entendo que as formas de racionalizar e de vivenciar experiências jurídicas são sempre orientadas a partir das óticas e das lógicas que fazem sentido para uma coletividade e seus interesses. Em todo o caso, a discussão destes autores - entre outros - parece pertinente já que permite iluminar alguns aspectos do que está em jogo quando analisamos as práticas e discursos da Fokupers, que produzem uma defesa bastante clara de certo tipo de concepções jurídicas em relação a outras. 
Ao proporem que os casos de violência doméstica sejam reconhecidos como ofensas graves à dignidade de sujeitos específicos, circunscrevendo-os em concepções morais e éticas sobre direitos, os agentes da Fokupers operam, me parece, orientados por percepções fundamentadas em valores universalizados, o que é em si produto de visões de mundo particulares. Do mesmo modo, ao se valerem de regulamentos, leis, códigos e normas para pautarem a luta pelos direitos das mulheres e ao defenderem formas específicas de produzir reparações, os agentes dessa ONG não se limitam a executar o simples acompanhamento das mulheres aos tribunais, o acolhimento e o esclarecimento de dúvidas; eles trabalham disseminando os valores que os mobilizam, reforçando uma agenda política e garantindo, a partir daí, o compartilhamento de concepções ou modos jurídicos de ver e de organizar o mundo social (Rosen 2006) com sujeitos que, talvez, ainda não atuem de acordo com os mesmos valores e sensibilidades jurídicas. ${ }^{12}$ Com isso, deve-se criar, segundo os agentes da organização, relações significadas a partir de um reconhecimento atento dos direitos individuais, da inviolabilidade dos corpos (que é questionada pelos atos de agressão), dentre outros efeitos operados e produzidos pela sociedade, ou, pelo menos neste contexto, por uma parte da sociedade engajada com agendas políticas específicas. É justamente esta parcela da sociedade (constituída pela Fokupers e agentes envolvidos nos processos de conscientização) que, visando operacionalizar a reprodução de sensibilidades jurídicas moderno -legais, recorre a formas de "convencionalização coletiva" (Rosen 2006), para, no mínimo, ampliar essas formas de pensar o fenômeno da violência doméstica, por meio de exercícios práticos de simulação e de elaboração do mundo de acordo com os termos jurídicos dos códigos e das leis assinadas e acionadas pelo Estado leste-timorense, convidando diferentes sujeitos à inserção no mundo jurídico-legal do/para o tratamento da violência doméstica.

Parece pertinente pensar que o que se está produzindo são a criação e a disseminação de uma cultura legal e judicial, a partir de pedagogias jurídicas. São orientações jurídico-judiciais que não são criadas/passadas pelos "operadores do direito", mas sim por pessoas que operam com o direito. Não são juízes, promotores ou defensores públicos, representantes do Estado, mas sim membros da sociedade civil que operacionalizam estes processos de defesa das instituições legais e que, ainda assim, conseguem gerar "relações ordenadas" entre pessoas (Rosen 2006) e em relação às formas de resolução de conflitos através de processos educativos. São atores que se valem dos "olhos do direito"

12 As sensibilidades jurídicas, tomando novamente de empréstimo a categoria cunhada por Geertz, são consideradas como um "complexo de caracterizações e suposições, estórias sobre ocorrências reais, apresentadas através de imagens relacionadas a princípios abstratos” (Geertz 1997: 325). São noções abstratas, construídas e significadas socialmente sobre os fenômenos reais ocorridos numa sociedade, que são positivados ou não a partir de princípios locais. 
(Geertz 1997: 259) para produzirem sujeitos, agentes e agências nos novos cenários que se constroem no erguimento daquele Estado-nação.

Uma última questão a esse respeito é o porquê de se falar aqui em "pedagogias jurídicas” e não em "pedagogias judiciais”, por exemplo. As atividades da Fokupers, analisadas sob o espectro de ações com potencial educativo, através de projetos de reorientação de comportamentos e também de aconselhamento, baseiam-se, principalmente, na "cobrança por direitos", no incentivo ao acionamento de instâncias judiciais estatais e no afastamento das formas locais de resolução de disputas - ao menos no que concerne à ocorrência de casos de violência doméstica. A Fokupers reconhece o sistema de justiça como aquele adequado para lidar com a questão, legitimando que se empenhe o que se tem chamado no Brasil de judicialização da violência doméstica e de outros conflitos interpessoais (Rifiotis 2008, 2014). Entretanto, essa não parece ser a única finalidade das atividades. Elas também se empenham em dar corpo às demandas por reconhecimento (Oliveira 2010), municiando sujeitos de diferentes grupos com saberes e recursos discursivo-materiais sobre igualdade de gênero e sobre outros direitos das mulheres, cobrando pelo legítimo exercício destes.

Todo este complexo que combina demandas e orientações de ordem prática (comportamental) e ideológica não poderia ser adequadamente caracterizado se fosse reduzido à sua parte concernente ao recurso judicial dos tribunais para resolver os casos de violência doméstica. Dado o seu caráter mais amplo, de leitura sobre o mundo e sobre determinados fenômenos sociais, envolvendo outros aspectos das diferentes arenas da vida social em Timor-Leste, especialmente na agenda da igualdade de gênero, parece mais adequado propor que as atividades da Fokupers compõem um hall de pedagogias jurídicas, não apenas judiciais, como me pareceriam ser exclusivamente a orientação do comportamento das mitra nos tribunais e o recurso à polícia/tribunais para resolução dos conflitos de violénsia doméstika.

Uma análise semelhante ao recurso a pedagogias jurídicas no contexto brasileiro tem sido elaborada por Brochado (2006), que discute formas através das quais tem se intentado produzir uma educação para a cidadania por meio de conhecimentos jurídicos e sobre direitos de modo acessível e que escape aos modelos tradicionais de ensino nas escolas de direito para a formação profissional. A utilização da categoria estaria ligada à formação e conscientização de cidadãos, que não seria feita exclusivamente por juristas, tornando estes conhecimentos acessíveis e permitindo que as pessoas recebessem uma formação jurídica para sua constituição enquanto sujeito/cidadão.

Uma ressalva ao contexto de ação da Fokupers em Timor-Leste é a de que lá se trataria, em grande medida, da "reformação jurídica" dos indivíduos, uma vez que está em jogo, em seus projetos, a "reorientação" dos sujeitos, de suas concepções e percepções sobre direitos, formas de resolução de disputas e acesso ao sistema de justiça do Estado. Faço uso da ideia de pedagogia jurídica, 
também inspirado na ideia de "pedagogia econômica" discutida por Kelly Silva (2016) para indicar como diferentes projetos estatais - em sua maioria - têm sido desenvolvidos para modificar a forma como as populações leste-timorenses utilizam seus recursos econômicos e materiais, visando a realocação de bens que seriam trocados em regimes de dádiva para serem vendidos como mercadorias.

\section{CONSIDERAÇÕES FINAIS}

Ao etnografar algumas práticas da Fokupers ressaltei seu caráter potencialmente transformador, por desenvolver atividades que visam educar, reeducar, orientar e reorientar sujeitos, e que pautam-se por saberes específicos, os quais se fundamentam no direito moderno-ocidental e suas lógicas próprias de funcionamento. Mesmo que esse seja o foco e o objetivo das atividades da Fokupers e, do mesmo modo, seja o centro de nossa discussão, o fenômeno aqui discutido ainda permite algumas proposições que se faz necessário explorar com caráter conclusivo.

A primeira delas é sobre a emergência de sinalizar a forma como a LCVD parece estar sendo utilizada com finalidades diversas, o que dá a ela novas possibilidades de vida social. Vimos aqui que, em diferentes momentos, a Lei n. ${ }^{\circ} 7 / 2010$ tem sido instrumentalizada pela Fokupers em outros contextos e com outras finalidades, que não apenas para o enquadramento criminal dos atos de violência doméstica (utilizado na polícia e nos tribunais), revelando certa utilização criativa da mesma. Uma das faces dessa utilização criativa é a mobilização da LCVD enquanto bandeira política, atestando ou servindo como prova de que teria havido avanços na luta pelos direitos das mulheres e que não haveria espaço para a aceitação da violência doméstica no país. Outra face seria a instrumentalização da Lei n. ${ }^{\circ} 7 / 2010$ com finalidade educativa, isto é, tomando-a nas atividades da ONG por ter sistematizado em seu texto as formas entendidas como sendo de violência doméstica (em suas distintas possibilidades), como alerta para uma mudança de comportamento e como materialização das bases e ansiedades políticas para a igualdade de gênero.

Para as mitra, especialmente aquelas que participam de atividades de socialização, a Lei contra a Violência Doméstica aparece não só como ferramenta educativa, mas também como instrumento de poder para as mulheres, que poderiam utilizá-la como recurso de "alerta" caso corressem riscos de sofrer violência doméstica em suas casas, uma vez que eram ensinadas que, denunciando os agressores, estes poderiam responder penalmente por seus atos. Essa face "alertadora" da LCVD era apresentada também aos multiplicadores, para que estes pudessem argumentar a esse respeito em suas futuras atividades, reorientando eventuais comportamentos violentos. 
A noção de "processos de regulamentação" de Sally Falk Moore (1978) é inspiradora para refletir sobre a vida social da LCVD, uma vez que percebemos que esta tem sido objeto de manuseios diversos. Segundo a autora, estes processos de regulamentação seriam "esforços de organizar e controlar comportamentos através do uso de regras explícitas" (Moore 1978: 2-3), que deveriam ser percebidos por meio das previsões das regras em si (nas leis e nos códigos) e, também, nas ocasiões em que elas são evocadas para orientar comportamentos desejados em contextos específicos, para além da letra da lei. Isso permite perceber - entre outras coisas discutidas pela autora - os espaços de consolidação das normas nos contextos práticos e empíricos da vida por meio de sua utilização. É a processos como estes que me volto para ressaltar o modo como a LCVD ganha vida social ativa nas mãos da Fokupers, enquanto recurso pedagógico, instrumento político e de mobilização coletiva de sujeitos, para além de suas funções estritamente executivas. ${ }^{13}$

Outro efeito ou consequência da vida social da LCVD que tem transparecido - ao menos a partir das experiências com a Fokupers - é a ampliação da noção da violência doméstica, vista como algo condenável e insultante da dignidade das mulheres. ${ }^{14}$ Não se trata de dizer que agora, diferentemente de momentos anteriores, como analisado por Simião (2015), os atos de violénsia doméstika sejam maiores ou mais inadmissíveis. Trata-se de perceber, primeiramente, que o trabalho da Fokupers se dedica a promover o "acionamento coletivo" perante os insultos morais (Oliveira 2011 ) causados pela violência doméstica, por meio da ampliação do reconhecimento de que diversos atos (incluindo agressões físicas) são atitudes inadmissíveis. Em suas atividades, a ONG parece estar garantindo que mais pessoas sejam alcançadas para compartilhar da condenação moral dos atos de uso da força física caracterizados como sendo de violência doméstica. Isso fica mais claro quando reconhecemos que, em suas atividades, a Fokupers não se limita a atender/orientar as mulheres que sofreram agressões, mas as auxilia a reconhecer como graves e denunciáveis quaisquer outras agressões, cometidas contra quaisquer outras mulheres, ao mesmo tempo que faz isso com outros agentes, como nos treinamentos.

Neste sentido, mesmo que as mitra, ao prestarem queixas contra seus agressores, tenham sido motivadas pela indignação gerada no ato da agressão sofrida e tenham acionado a esfera judicial por terem se sentido ofendidas - compartilhando (talvez) elas mesmas da noção de violência como algo inaceitável -,

13 Processo que inclui os outros mecanismos legais e normas utilizados no contexto, como o Código Penal leste-timorense, o texto da CEDAW, etc. O foco dado à LCVD, contudo, é de meu interesse por seu potencial particular.

14 Mesmo antes da promulgação da LCVD, lutava-se para propagar a ideia de que a violénsia doméstika era um crime (Simião 2015: 262); entretanto, agora se pode recorrer a este argumento com embasamento legal e apoiado em outras convenções como a CEDAW e o próprio Código Penal do país, aprovado em 2009. 
elas são orientadas e encorajadas pela ONG a disseminarem sentimentos deste tipo em suas comunidades, famílias, aldeias ou sukus, para que outras mulheres façam o mesmo, movidas pela indignação moral pertinente face à situação, isto é, movidas pelo entendimento de que aqueles atos dirigidos a elas são atos de desconsideração, são insultos morais (Oliveira 2008, 2011 ). ${ }^{15}$

É neste sentido que falo na ampliação do reconhecimento do insulto à dignidade das mulheres, isto é, o acionamento do insulto para terceiros (Oliveira 2011), não apenas para aquelas que sofreram com a agressão. Este seria um tipo de insulto gerado por atos que, ao se dirigirem à dignidade das mulheres de modo coletivo, careceriam e seriam passíveis de reparação institucional (Oliveira 2008), esta entendida por minhas interlocutoras como sendo aquela ofertada no sistema formal de justiça. Não se deve deixar de notar, ainda, a diversificação e a multiplicação dos sujeitos envolvidos com a causa, para promover o espraiamento da condenação moral da violência doméstica.

Por fim, o que a organização parece promover são formas particulares de experiência com recurso ao direito, além da disseminação de sensos de justiça e de sensibilidades jurídicas (Geertz 1997) específicas, por meio das pedagogias que ressaltam a legitimação de uma esfera judicial (estatal) em detrimento de outra, numa lógica de sistemas jurídicos "concorrenciais", do ponto de vista da ONG, que opera através de recomendações para que os sujeitos se desloquem de um espaço (ou de espaços) de resolução de conflitos, o(s) das aldeias, para outro, o judicial, estatal. ${ }^{16}$

15 Apesar de a discussão de Luís Roberto Cardoso de Oliveira $(2010,2011)$ sobre os insultos morais considerar que estes seriam oriundos de atos de difícil materialização em provas físicas, o que diverge das agressões que configuram violência doméstica, que, geralmente, deixam marcas como hematomas e escoriações, reflito aqui sobre o sentido moral que acompanha as agressões, referindo-me aos traumas e ao sentimento de humilhação que as agressões características de violência doméstica gerariam (Fokupers 2012a, 2012b). Ainda assim, há expressões da violência doméstica que não teriam, de fato, expressões físicas, como a violência psicológica, emocional e a violência econômica, retratadas de acordo com a LCVD. Considero, portanto, tal noção pertinente para tratar de expressões da violência doméstica.

16 Este é um ponto de vista que parece operar mais para as ONGs em geral do que para os operadores do direito. Por vezes, juízes têm acatado as decisões estabelecidas nos processos locais de mediação de conflitos ocorridos nas aldeias, o que descontenta algumas organizações não governamentais (Meneses et al. 2017). 


\section{BIBLIOGRAFIA}

BROCHADO, Mariah, 2006, "Pedagogia jurídica para o cidadão: formação da consciência jurídica a partir de uma compreensão ética do direito", Revista da Faculdade de Direito da Universidade Federal de Minas Gerais, 48: 159-188, disponível em < https://www.direito. ufmg.br/revista/index.php/revista/article/view/1461 > (última consulta em outubro de 2019).

FOKUPERS, 2012a, Domestic Violence: When My Home Is No Longer a Safe Place for Me. Dili, Fokupers.

FOKUPERS, 2012b, Bride Price and Domestic Violence in Timor Leste: A Comparative Study of Married-in and Married-out Cultures in Four Districts. Dili, Fokupers.

GEERTZ, Clifford, 1997, O Saber Local: Novos Ensaios em Antropologia Interpretativa. Petrópolis, Vozes.

GPI - GABINETE PARA A PROMOÇÃO DA IGUALDADE, 2003, Documento de Orientação para a Legislação contra a Violência Doméstica. Dili, Gabinete para a Promoção da Igualdade (mimeografado).

HUNT, Janet, 2004, "Building a new civil society: NGOs in East Timor", New Community Quarterly, 2 (1), disponível em < https://etan.org/et2004/october/22/29buildng.htm > (última consulta em outubro de 2019).

JANNISA, Gudmund, 2002, "Towards a civil society: the long and arduous struggle of East Timor", em G. Jonsson (org.), East Timor: Nationbuilding in the 21st Century. Estocolmo, The Swedish Insitute of International Affairs, 39-79.

JSMP - JUDICIAL SYSTEM MONITORING PROGRAMME, 2013, Law Against Domestic Violence: Obstacles to Implementation Three Years On. Dili, Judicial System Monitoring Programme.

MENESES, Maria Paula, et al., 2017, Para Uma Justiça de Matriz Timorense: O Contributo das Justiças Comunitárias. Dili, Comissão para a Reforma Legislativa e do Sector da Justiça.

MOORE, Sally Falk, 1978, Law as Process: An Anthropological Approach. Londres, Routledge and Keegan Paul.

OLIVEIRA, Luís Roberto Cardoso de, 2008, “Existe violência sem agressão moral?”, Revista Brasileira de Ciências Sociais, 23 (67): 135-146, disponível em < http:/www.scielo.br/pdf/ rbcsoc/v23n67/10.pdf > (última consulta em outubro de 2019).

OLIVEIRA, Luís Roberto Cardoso de, 2010, "A dimensão simbólica dos direitos e a análise de conflitos”, Revista de Antropologia, 53 (2): 45 1-473, disponível em < http://www.revistas.usp.br/ra/article/view/36432/40414 > (última consulta em outubro de 2019).

OliveirA, Luís Roberto Cardoso de, 201 1, Direito Legal e Insulto Moral: Dilemas da Cidadania no Brasil, Quebec e EUA. Rio de Janeiro, Garamond.

RIFIOTIS, Theophilos, 2008, "Judiciarização das relações sociais e estratégias de reconhecimento: repensando a 'violência conjugal' e a 'violência intrafamiliar' ", Katálysis, 11 (2): 225-236, disponível em < https://periodicos.ufsc.br/index.php/katalysis/article/view/S 14 14-49802008000200008 > (última consulta em outubro de 2019).

RIFIOTIS, Theophilos, 2014, "Judicialização dos direitos humanos, lutas por reconhecimento e políticas públicas no Brasil: configurações de sujeito", Revista de Antropologia, 57 (1): 119-144, disponível em < http://www.revistas.usp.br/ra/article/view/87755 > (última consulta em outubro de 2019).

ROSEN, Lawrence, 2006, Law as Culture: An Invitation. Princeton, Princeton University Press. 
SANTOS FILHO, Miguel Antonio dos, 2016, A Conformação de Uma Sociedade Civil e a Consolidação da Violensia Domestika: Faces da Transposição da Modernidade em Timor-Leste. Brasília, Universidade de Brasília, trabalho de conclusão de curso de bacharelado em Antropologia.

SANTOS FILHO, Miguel Antonio dos, 2017, "O combate à violensia domestika na Fokupers: práticas de mediação e de transposição da modernidade em Timor-Leste”, em L. Eilbaum, P. Schuch e G. F. Chagas (orgs.), Antropologia e Direitos Humanos 7. Rio de Janeiro, Associação Brasileira de Antropologia, 149-179.

SEPI - SECRETARIA DE ESTADO PARA PROMOÇÃO DA IGUALDADE, 2012, National Action Plan on Gender-Based Violence. Dili, Secretaria de Estado para Promoção da Igualdade.

SILVA, Kelly, 2016, "Administrando pessoas, recursos e rituais: pedagogia econômica como tática de governo em Timor-Leste", Horizontes Antropológicos, 22 (45): 127-153, disponível em < http://www.scielo.br/scielo.php?script=sci_arttext\&pi$\mathrm{d}=$ S0104-7 $1832016000100127 \& \operatorname{lng}=$ en \&nrm = iso/v22n45/0104-7 183-ha-22 -45-0127.pdf\&tlng=pt > (última consulta em outubro de 2019).

SIMIÃO, Daniel Schroeter, 2005, "O feiticeiro desencantado: gênero, justiça e a invenção da violência doméstica em Timor-Leste”, Anuário Antropológico, 2005: 127-154.

SIMIÃO, Daniel Schroeter, 2007, “'Madam, it's not so easy': modelos de gênero e justiça na reconstrução timorense”, em K. Silva e D. S. Simião (orgs.), Timor-Leste por Trás do Palco: A Cooperação Internacional e a Dialética da Formação do Estado. Belo Horizonte, Editora UFMG, $210-233$.

SIMIÃo, Daniel Schroeter, 2015, As Donas da Palavra: Gênero, Justiça e a Invenção da Violência Doméstica em Timor Leste. Brasília, Editora Universidade de Brasília.

UNIFEM - FUNDO DE DESENVOLVIMENTO DAS NAÇÕES UNIDAS PARA A MULHER, 2007, Convenção sobre a Eliminação de Todas as Formas de Discriminação contra a Mulher. Dili, Unifem, documento mimeografado.

WAGNER, Roy, 1981, The Invention of Culture. Chicago, The University of Chicago Press. 